\title{
Expanding the Scope of Palladium-Catalyzed B - N Cross- Coupling Chemistry in Carboranes
}

\author{
Xin $\mathrm{Mu}^{1}$, Morgan Hopp ${ }^{1}$, Rafal M. Dziedzic ${ }^{1}$, Arnold L. Rheingold ${ }^{2}$, Ellen M. Sletten, ${ }^{1}$ Jonathan C. Ax- \\ tell*,1, Alexander M. Spokoyny*,1 \\ ${ }^{1}$ Department of Chemistry and Biochemistry, University of California, Los Angeles, 607 Charles E. Young Drive East, Los \\ Angeles, California 90095, United States \\ ${ }^{2}$ Department of Chemistry and Biochemistry, University of California, San Diego, 9500 Gilman Drive, La Jolla, California \\ 92093, United States Supporting Information Placeholder
}

\begin{abstract}
Over the past several years, a number of strategies for the functionalization of dicarba-closo-dodecaboranes (carboranes) have emerged. Despite these developments, $\mathrm{B}-\mathrm{N}$ bond formation on the carborane scaffold remains a challenge due to the propensity of strong nucleophiles to partially deboronate the parent closo-carborane cluster into the corresponding nido form. Here we show that azide, sulfonamide, cyanate, and phosphoramidate nucleophiles can be straightforwardly cross-coupled onto the B(9) vertices of the $o$ - and $m$-carborane core from readily accessible precursors without significant deboronation by-products, laying the groundwork for further study into the utility and properties of these new B-aminated carborane species. We further showcase select reactivity of the installed functional groups highlighting some unique features stemming from the combination of the electron-donating $\mathrm{B}(9)$ position and the large steric profile of the B-connected carborane substituent.
\end{abstract}

\section{INTRODUCTION}

Icosahedral carboranes are a unique class of molecules characterized by their multi-center, two-electron delocalized bonding, which ultimately gives rise to kinetic stability and reactivity not observed for more typically encountered tri-coordinate boranes. ${ }^{1}$ In particular, these 12 -vertex boron clusters - which exist as ortho-, meta-, or para- isomers, depending on the relative carbon vertex arrangement - have been applied in a variety of research areas ranging from ligand design to the development of luminescent materials and pharmacophores. ${ }^{2}$ Generally, these molecular building blocks have been leveraged for their steric bulk (nearly isosteric with adamantane and $\sim 40 \%$ larger by volume than benzene) $)^{3}$ as well as for their vertex-dependent electronic influence. ${ }^{3 \mathrm{~g}, 4}$ The continued advancement of these molecules is predicated on the ability to forge $\mathrm{B}-\mathrm{R}$ and $\mathrm{C}-\mathrm{R}$ bonds for further elaboration. ${ }^{5}$ Since the $\mathrm{C}-\mathrm{H}$ vertices of carboranes are known to be relatively acidic and are easily deprotonated, the chemistry at these vertices was first explored and has been extensively developed. ${ }^{6}$ In contrast, only until recently have a breadth of methods emerged for selective B-H vertex functionalization, many of which are transition metal-catalyzed. ${ }^{7}$

Our group has been interested in the development of metal-catalyzed cross-coupling methodology for polyhedral boron clusters. Though a number of methods now exist for the (metal-catalyzed) construction of $\mathrm{C}-\mathrm{N}$ bonds from aryl halides (Figure $1 \mathrm{~A})$, a persistent challenge in the context of carborane functionalization is the introduction of nitrogen-based substituents onto the boron cluster cage, given the known propensity of, in particular, $O$-carborane to deboronate in the presence of strongly nucleophilic reactants (Figure $1 \mathrm{~B}){ }^{8}$ the resulting deboronated cage is known to bind the Pd center, effectively shutting down cross-coupling catalysis. ${ }^{9}$ Furthermore, the propensity for deboronation with substituted $o$-carboranes can be so high that some of these species undergo deboronation even under highly acidic conditions. ${ }^{10}$

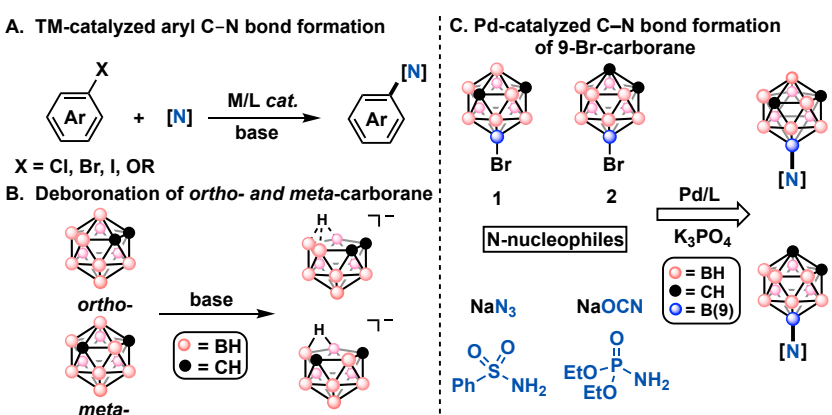

Figure 1. Standard conditions for $\mathrm{C}-\mathrm{N}$ bond formation under transition metal (TM)-catalyzed amination conditions (A) are often incompatible with carboranes due to deboronation (B) under strongly basic conditions. This problem can be circumvented with masked $N$-nucleophile coupling partners (C).

Consequently, translating nucleophiles used in the amination of organic molecules has lagged behind for carborane-based electrophiles under transition metal catalysis. Some early crosscoupling strategies for $\mathrm{B}-\mathrm{N}$ bond formation were independently developed by Hawthorne and Beletskaya using B-iodocarboranes and were primarily focused on the use of paraand meta-based substrates due to their improved stability towards deboronation. ${ }^{11}$ While Hawthorne reported a successful synthesis of several 9-amido-o-carborane substrates via this route, the authors were unable to successfully convert it to the corresponding amine via hydrolysis under acidic or basic conditions. Besides cross-coupling strategies, several other notable methods using activated B-centered electrophiles have also been developed. These methods, however, employ relatively unstable precursors and multistep processes are required for their synthesis. ${ }^{12}$ In 2016, our group discovered B-bromocarboranes - previously assumed to be unreactive cross-coupling substrates - can act as competent electrophiles in Pd-catalyzed cross-coupling chemistry, leading to successful substitutions at various B-based vertices from the corresponding brominated carboranes. ${ }^{13}$ Capitalizing on this discovery, we recently syn- 
thesized 9-azido-ortho-carborane from the corresponding brominated precursor, ${ }^{14}$ notably, while this chemistry aligns with the apparent generality of other cross-coupling reactions involving B-bromocarborane electrophiles, ${ }^{7}$ to our knowledge an analogous Pd-catalyzed cross-coupling strategy to synthesize aryl azides from aryl (pseudo)halide electrophiles has not been disclosed. Importantly, this product could ultimately be reduced to the free amine under acidic conditions, constituting the first synthesis of primary amine derivative at $\mathrm{B}(9)$ of $o$-carborane. Here, we showcase an expanded reactivity scope for $\mathrm{B}-\mathrm{N}$ bond formation via cross-coupling chemistry of both $o$ - and $m$-carborane B-brominated electrophiles with cyanate, sulfonamide, and phosphoramidate nucleophiles (Figure 1C), with a particular eye on subsequent reactivity of these coupled B-functionalized products. This contribution expands known metal-catalyzed cross-coupling chemistry by introducing new functional groups available for attachment directly to boron vertices in carboranes.

\section{RESULTS AND DISCUSSION}

We initiated our studies with the coupling of $\mathrm{NaN}_{3}$ with 9-Br$m-\mathrm{C}_{2} \mathrm{~B}_{10} \mathrm{H}_{11}$ (1) under a variety of conditions using Pd-based precatalysts containing biaryl phosphine ligands. ${ }^{7 \mathrm{a}, 15}$ While reactions conducted in either 1,4-dioxane or toluene resulted in only partial conversion (see SI), we found that the use of 1,2dimethoxyethane as solvent furnished the desired product with complete conversion to the desired $9-\mathrm{N}_{3}-m-\mathrm{C}_{2} \mathrm{~B}_{10} \mathrm{H}_{11}$ product (1a) without deboronation, as judged by gas chromatographymass spectrometry (GC-MS) and ${ }^{11} \mathrm{~B}$ NMR spectroscopy. Employing the optimized conditions, 1a was isolated in $81 \%$ yield following silica gel chromatography. Infrared (IR) spectroscopic analysis revealed a diagnostic resonance at $2124 \mathrm{~cm}^{-1}$, corresponding to the asymmetric stretching frequency of the $\mathrm{N}_{3}$ group (see SI). It should be noted that that Grushin previously synthesized 1a but through the intermediacy of sensitive B-carboranyliodinium precursors. ${ }^{16}$ Furthermore, we successfully characterized 1a through single crystal X-ray diffraction on crystals grown from a concentrated pentane solution (Figure 2); we also synthesized the $o$-carborane analogue of $1 \mathbf{a}(\mathbf{2 a})$ and crystallographically characterized this product (see SI). Compounds 1a and 2a show comparable bond lengths and angles, the full summary of which may be found in the Supporting Information. Notably, compared with reported crystal structure of carboranyl azide with the azide group on the carbon vertex of $o$-carborane,${ }^{17}$ the $\mathrm{B}-\mathrm{N}$ bond of $2 \mathrm{a}(\mathrm{B}-\mathrm{N} 1=1.503(4) \AA)$ is longer than the $\mathrm{C}-\mathrm{N}$ bond $(\mathrm{C}-\mathrm{N} 1=1.4282(13) \AA)$ and the $\mathrm{N} 1$ - N2 bond length of $2 \mathbf{a}(1.215(3) \AA)$ is shorter than the corresponding $\mathrm{N}-\mathrm{N}$ bond length in the $C$-bound derivative (1.2594 (13) $\AA$ ); the N2 - N3 bond lengths of these linkage isomers are almost identical (for 2a, N2 - N3 = 1.138(3) $\AA$; for the $C$-bound derivative, $1.1219(14) \AA)$. The asymmetric stretching frequency of the azide group in $\mathbf{1 a}\left(2124 \mathrm{~cm}^{-1}\right)$ compares well with that reported for $\mathbf{2 a}\left(2121 \mathrm{~cm}^{-1}\right) \cdot{ }^{14} \mathrm{Xie}$ and co-workers previously reported a stretching frequency of $2149 \mathrm{~cm}^{-1}$ for the synthesized 3- $\mathrm{N}_{3}-O$-carborane. ${ }^{12 b}$ This appreciable difference in azide stretches based on vertex-attachment stands in contrast to analogous aryl systems in which it has been noted that the electronic landscape of the aryl ring has little measurable effect on the azide IR stretching and bending frequencies. ${ }^{18}$ This observation is furthermore consistent with previous work indicating that carborane-based substituents can exert a dramatically different inductive effect depending on their vertex positional attachment. ${ }^{2 \mathrm{~g}, 2 \mathrm{k}, 5}$

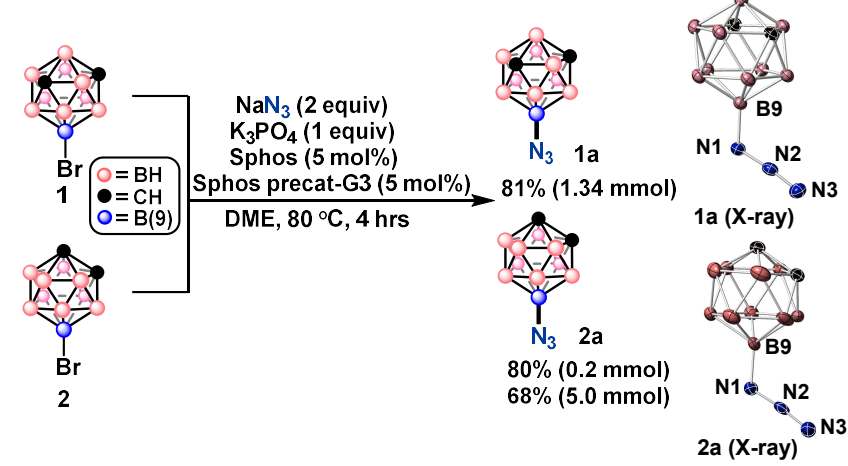

Figure 2. Using standard carborane coupling conditions, azide undergoes Pd-catalyzed cross-coupling with B-bromocarboranes on $5 \mathrm{mmol}$ scale without deboronation. Both $o$ - and $m$ carborane derivatives have been crystallographically characterized (see SI for details).

The wealth of chemistry known with the azide functional group appended onto carbon-based skeletons of organic molecules ${ }^{19}$ prompted a brief exploration of its reactivity as a carborane substituent. For corresponding carborane-based azides, a scattering of reports detail their reactivity, which appears largely to be Bvertex-dependent, consistent with the electronic non-uniformity of the carborane cage and the resulting electronic influence on bound substituents. ${ }^{3 \mathrm{~g}, 4}$ For example, while both Sousa-Pedrare $^{20}$ and Kennedy ${ }^{21}$ have reported attempted Staudinger reductions of carboranyl azides $(\mathrm{B}(3)$ - and $\mathrm{C}(1)$-bound, respectively, the former is found to proceed in THF under slightly less forcing conditions whereas the latter can be trapped at the phosphazide stage, and ultimate formation of the corresponding iminophosphorane requires more forcing conditions. In addition, Xie reported the reaction of $3-\mathrm{N}_{3}-O-\mathrm{C}_{2} \mathrm{~B}_{10} \mathrm{H}_{11}$ with diethylacetylene dicarboxylate and the subsequent formation of a substituted triazole. ${ }^{22}$ Here, we find that $\mathbf{1 a}$ and $\mathbf{2 a}$ both react with diethylacetylene dicarboxylate under reflux conditions to form the substituted triazole products ( 3 and 4 , respectively, Figure 3A,B). In addition, 2a also reacts with trimethylsilylacetylene under similar conditions to afford the expected triazole product 5 in $>20: 1$ regioisomeric excess (Figure $3 \mathrm{~B}$ ). The exceptional stability of $\mathbf{1 a}$ and $\mathbf{2 a}$ which has enabled the cycloaddition reactions under heating conditions is consistent with Grushin's observation, ${ }^{16}$ and in stark contrast with report on the rapid decomposition of 1 -azido-o-carborane even at low temperatures reported by Jones. ${ }^{23}$ Relatively harsh conditions required for these transformations to proceed are consistent with the early observations by Jones and co-workers who made a note on the exceptional stability of $\mathbf{2 a}$ in the context of 1,3-dipolar reactions with olefins. ${ }^{23}$

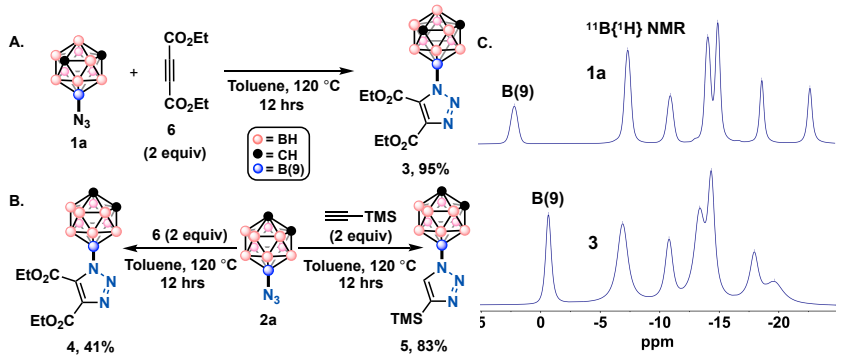

Figure 3. Thermal azide-alkyne cycloadditions of functionalized alkynes with 9- $\mathrm{N}_{3}-m-\mathrm{C}_{2} \mathrm{~B}_{10} \mathrm{H}_{11}(\mathrm{~A})$ and 9- $\mathrm{N}_{3}-O-\mathrm{C}_{2} \mathrm{~B}_{10} \mathrm{H}_{11}$ (B). (C) ${ }^{11} \mathrm{~B}\left\{{ }^{1} \mathrm{H}\right\}$ NMR spectra of substrate $1 \mathrm{a}$ and cycloaddition product $\mathbf{3 a}$. 
Beyond azide, we wondered whether other nucleophiles such as sulfonamide, cyanate, and phosphoramidate, all of which bear nitrogen atoms as part of one or more resonance forms, were also amenable to the discovered cross-coupling method. Using analogous conditions developed for azide coupling, we find that both sulfonamide- and phosphoramidate-based nucleophiles can be successfully attached to $\mathbf{1}$ and $\mathbf{2}$. In all cases, full conversion is reached when conducting the reaction in DME at $80^{\circ} \mathrm{C}$ with 1.2 equivalents of the corresponding nucleophile; the resulting $m$ - and $o$-carborane products $\mathbf{1 b} / \mathbf{2 b}$ and $\mathbf{1 c} / \mathbf{2 c}$ were isolated in good yield (Figure 4). In addition, $\mathbf{1 b}$ and $\mathbf{1 c}$ were crystallographically characterized and display the expected connectivity (see SI). For $\mathbf{1 b}$, the $\mathrm{B}-\mathrm{N}$ bond is slightly longer than a carborane structure with $\mathrm{B}(4)$ vertex substituted by phenyl sulfonamide $(\mathrm{B}-\mathrm{N}=1.482(5) \AA$ compared to $\mathrm{B}-\mathrm{N}=1.476(3) \AA$ in the literature report). ${ }^{24}$ For $1 \mathrm{c}$, the $\mathrm{B}-\mathrm{N}$ bond $(\mathrm{B}-\mathrm{N}=1.4779$ (19) Å) is slightly shorter than $\mathbf{1 b}$.

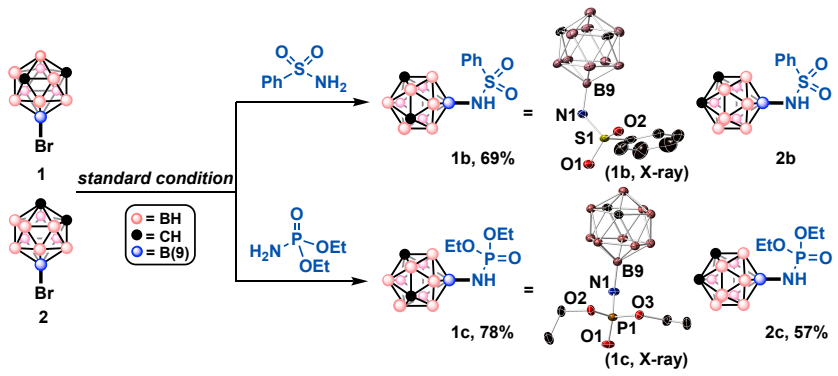

Figure 4. Phosporamidate and sulfonamide nucleophiles undergo a successful Pd-catalyzed cross-coupling with B-bromocarboranes under the standard conditions. $* \mathbf{2} \mathbf{b}$ was inseparable from free sulfonamide and could not be isolated in pure form. For full crystallographic details, see SI.

Given the isoelectronic relationship of cyanate with azide, and the potential for elaboration of cyanate substituents with incipient nucleophiles, we sought to develop conditions for synthesizing cyanate-containing carboranes. Though uncommon, cyanate cross-coupling with aryl electrophiles has been previously disclosed by Buchwald and co-workers, ${ }^{25}$ and while strategies for incorporating the isocyanate group onto (car)borane clusters have been reported, ${ }^{26}$ all involve multi-step protocols rather than direct isocyanate installation. Our direct cross-coupling method, however, ultimately proved successful. While the conditions reported by Buchwald were unsuccessful for our boron cluster substrates, we find that conditions similar to those employed above resulted in efficient cyanate coupling. Heating 1 or 2 with an excess of sodium cyanate in DME at $110^{\circ} \mathrm{C}$ for 24 hours under $\mathrm{Pd}$ catalysis resulted in conversion to the desired NCO-substituted carboranes $\mathbf{1 d}$ and $\mathbf{2 d}$, respectively (Figure 5). Subsequent optimization revealed that an excess of cyanate is necessary in order to drive the reaction to completeness. Additives employed to reduce the loading of $\mathrm{NaNCO}$ in DME by increasing solubility, such as $\mathrm{NEt}_{3}$ or $\mathrm{NBu}_{4} \mathrm{Br}$, were detrimental to the reaction outcome. The $\mathrm{B}-\mathrm{N}$ connectivity of the isocyanate-containing products was confirmed crystallographically (see SI for full crystallographic details). In $\mathbf{2 d}$, the $\mathrm{B}-\mathrm{N}$ bond length is $1.459(5) \AA$ and does not deviate significantly from that in 1b and 1c. The $\mathrm{N} 1-\mathrm{C} 3$ bond is shorter than a sterically hindered aryl isocyanate ${ }^{28}$ (2,6-Dipp- $\mathrm{C}_{6} \mathrm{H}_{4}-\mathrm{NCO}$; Dipp $=2,6-\mathrm{Pr}_{2}-$ $\mathrm{C}_{6} \mathrm{H}_{4}$ ) reported by Figueroa, but the $\mathrm{C} 3-\mathrm{O} 1$ bond lengths are almost identical $(\mathrm{C} 3-\mathrm{N} 1=1.157(5) \AA, \mathrm{C} 3-\mathrm{O} 1=1.187$ (4) $\AA$; for literature report, $\mathrm{C}-\mathrm{N}=1.191$ (2) $\AA, \mathrm{C}-\mathrm{O}=1.183$ (2) $\AA$ ). However, it should be highlighted that the $\mathrm{C}-\mathrm{N}$ bond of the terphenyl derivative was found to be $1.409(2) \AA$ whereas the corresponding B - N distance is 1.459(6) $\AA$; furthermore, despite the possibility of lone pair overlap with the aromatic system in the case of Figueroa's compound, the $\mathrm{C}-\mathrm{N}-\mathrm{C}$ angle strongly deviates from linearity $\left(140.53^{\circ}\right)$ whereas the analogous $\mathrm{B}-\mathrm{N}-\mathrm{C}$ angle in $\mathbf{1 d}$ is $155.78^{\circ}$, suggesting potential participation of nitrogen-based electron density in the molecular bonding framework. This formulation is borne out in the asymmetric $v_{\mathrm{NCO}}$ stretches: while common asymmetric aryl isocyanate frequencies resonate in the $\sim 2265-2275 \mathrm{~cm}^{-1}$ range,${ }^{29} \mathbf{1 d}$ and 2d show corresponding frequencies of $\sim 2297 \mathrm{~cm}^{-1}$ and $\sim 2314 \mathrm{~cm}^{-1}$, respectively, and are consistent with a previous report. $^{26 a}$ Similar observations were made for 3-NCO-ocarborane ${ }^{26 \mathrm{c}}$ which has a reported $v_{\mathrm{NCO}}$ in the range of $2310-$ $2325 \mathrm{~cm}^{-1}$, consistent with more electron-poor nature of the $\mathrm{B}(3)$ vertex of $o$-carborane, and with the trend observed for vertex-differentiated carboranylazides (vide supra). Surprisingly, 1-NCO-o-carborane has a reported $v_{\mathrm{NCO}}$ of $2258 \mathrm{~cm}^{-1} 26 \mathrm{~d}$ : based on inductive effects, it would be expected that the stretching frequency would be even higher than that of the $\mathrm{B}(3)$ derivative. However, Teixidor has previously suggested ${ }^{30}$ that $\mathrm{C}$-bound substituents with available lone pairs can donate electron density back into the cage with concomitant $\mathrm{C}-\mathrm{C}$ bond lengthening, which may in part explain the deviation in this trend. Unfortunately, at this point we are unable to compare this observation with the analogous azide system. Nevertheless, cage electronics clearly have an effect on the $v_{\mathrm{NCO}}$, as analogous carboranylisocyanates of the type $1-\left(\mathrm{OCN}\left(\mathrm{CH}_{2}\right)_{\mathrm{n}}\right) \mathrm{C}_{2} \mathrm{~B}_{10} \mathrm{H}_{11}$ display corresponding $v_{\mathrm{NCO}}$ of $2272 \mathrm{~cm}^{-1}(\mathrm{n}=2)$ and $2284 \mathrm{~cm}^{-1}(\mathrm{n}=3)^{31}$ and are more typical for alkyl/aryl isocyanates. ${ }^{29}$

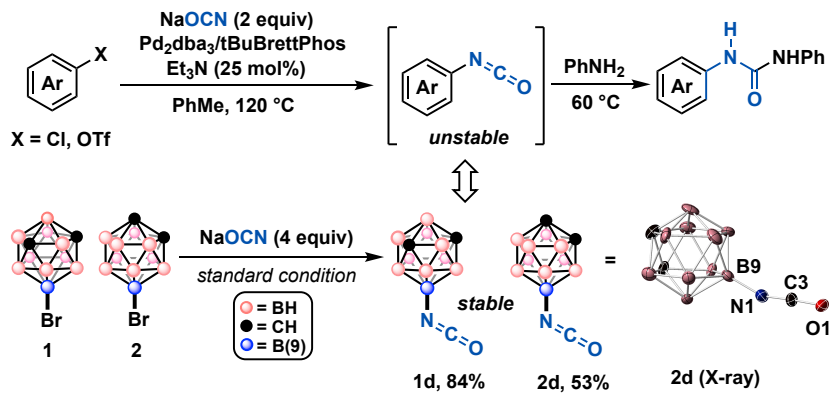

Figure 5. Sodium cyanate serves as a competent nucleophile for Pd-catalyzed cross-coupling with B-bromocarboranes $\mathbf{1}$ and 2. In contrast to more reactive aryl analogues (top), the carborane products display stability under ambient conditions. Product 2d has been crystallographically characterized (see SI for details).

We find that $\mathbf{1 d}$ and $\mathbf{2 d}$ can be isolated by column chromatography, which is remarkable given the characteristically high reactivity of the isocyanate group. In fact, these products appear stable to conditions under which isocyanates are typically reactive: while the aryl analogues can be treated directly with alcohols or amines to furnish the corresponding carbamates and ureas, we find that treating either $\mathbf{1 d}$ or $\mathbf{2 d}$ with an excess of $\mathrm{MeOH}$ or aniline at room temperature results in no reaction. This reactivity observed is consistent with that reported by Kalinin and coworkers (note that, $\mathbf{1 d}$ and $\mathbf{2 d}$ were obtained via a 5 step synthesis starting from $o$ - and $m$-carborane precursors), ${ }^{26 a}$ who suggested that significant heating is required in order to form the corresponding carbamate species. Isocyanates 1d and 2d also exhibit an apparent increased stability towards nucleophiles over B(3) and C-based congeners, although further sideby-side reactivity assessment is necessary to estimate the magnitude of these differences. ${ }^{26 a, c, d}$ It should be noted that some 
bulky arylisocyanates have also been reported to be resistant to nucleophilic attack, ${ }^{32}$ suggesting that the steric profile of the carborane cage in the reactivity at the - NCO unit cannot be ignored in these considerations. We are currently exploring the consequences of this deviation in typical reactivity with respect to generally more reactive aryl derivatives.

In summary, we have discovered that under Pd catalysis, both $o$ - and $m$-B-bromocarborane clusters can be successfully functionalized with a new class of $N$-nucleophiles without any apparent deboronation. The possibilities to subsequently functionalize these substrates at nitrogen potentially provide promising routes to further elaborated $N$-functionalized carborane-based molecules and materials that would be difficult to access otherwise. $^{33}$

\section{AUTHOR INFORMATION}

\section{Corresponding Author}

*spokoyny@chem.ucla.edu

* jaxtell@dow.com

\section{ORCID}

Alexander M. Spokoyny: 0000-0002-5683-6240

Jonathan C. Axtell: 0000-0002-5579-4296

Xin Mu: 0000-0002-1514-3210

Morgan Hopp: 0000-0003-4424-3429

Rafal M. Dziedzic: 0000-0002-4459-0554

Arnold L. Rheingold: 0000-0003-4472-8127

Ellen M. Sletten: 0000-0002-0049-7278

\section{Acknowledgements}

Support for this study was provided by NIGMS (R35GM124746 for A.M.S. and 1DP2GM13268 for E. M. S.) and Dreyfus Foundation (Camille Dreyfus Teacher Scholar Award for A. M. S.). The authors thank Dr. Robert D. Kennedy for thoughtful discussions.

\section{Notes}

The authors declare no competing financial interest.

\section{REFERENCES}

(1) (a) Lipscomb, W. N. Boron Hydrides; Benjamin: New York, 1963; (b) Schleyer, P. v. R.; Najafian, K. Stability and Three-Dimensional Aromaticity of closo-Monocarborane Anions, $\mathrm{CB}_{n-1} \mathrm{H}_{n}$, and closo-Dicarboranes, $\mathrm{C}_{2} \mathrm{~B}_{n-2} \mathrm{H}_{n}$. Inorg. Chem. 1998, 37, 3454-3470; (c) Chen, Z.; King, R. B. Spherical Aromaticity: Recent Work on Fullerenes, Polyhedral Boranes, and Related Structures. Chem. Rev. 2005, 105, 3613-3642; (d) King, R. B. Three-Dimensional Aromaticity in Polyhedral Boranes and Related Molecules. Chem. Rev. 2001, 101, 11191152.

(2) Selected recent contribution and references, see: (a) Julius, R. L.; Farha, O. K.; Chiang, J.; Perry, L. J.; Hawthorne, M. F., Synthesis and evaluation of transthyretin amyloidosis inhibitors containing carborane pharmacophores. Proc. Natl. Acad. Sci. 2007, 104, 4808-4813. (b) Douvris, C.; Ozerov, O. V., Hydrodefluorination of Perfluoroalkyl Groups Using SilyliumCarborane Catalysts. Science 2008, 321, 1188-1190. (c) Armstrong, A. F.; Lebert, J. M.; Brennan, J. D.; Valliant, J. F., Functionalized Carborane Complexes of the $\left[\mathrm{M}(\mathrm{CO})_{2}(\mathrm{NO})\right]^{2+}$ Core $(\mathrm{M}=99 \mathrm{mTc}, \mathrm{Re})$ : A New Class of Organometallic Probes for Correlated in Vitro and in Vivo Imaging. Organometallics 2009, 28, 2986-2992. (d) Beer, M. L.; Lemon, J.; Valliant, J.
F., Preparation and Evaluation of Carborane Analogues of Tamoxifen. J. Med. Chem. 2010, 53, 8012-8020. (e) Goto, T.; Ohta, K.; Fujii, S.; Ohta, S.; Endo, Y., Design and Synthesis of Androgen Receptor Full Antagonists Bearing a $p$-Carborane Cage: Promising Ligands for Anti-Androgen Withdrawal Syndrome. J. Med. Chem. 2010, 53, 4917-4926. (f) Dash, B. P.; Satapathy, R.; Gaillard, E. R.; Norton, K. M.; Maguire, J. A.; Chug, N.; Hosmane, N. S., Enhanced $\pi$-Conjugation and Emission via Icosahedral Carboranes: Synthetic and Spectroscopic Investigation. Inorg. Chem. 2011, 50, 54855493. (g) Spokoyny, A. M.; Machan, C. W.; Clingerman, D. J.; Rosen, M. S.; Wiester, M. J.; Kennedy, R. D.; Stern, C. L.; Sarjeant, A. A.; Mirkin, C. A., A coordination chemistry dichotomy for icosahedral carborane-based ligands. Nat. Chem. 2011, 3, 590-596. (h) Fey, N.; Haddow, M. F.; Mistry, R.; Norman, N. C.; Orpen, A. G.; Reynolds, T. J.; Pringle, P. G., Regioselective B-Cyclometalation of a Bulky o-Carboranyl Phosphine and the Unexpected Formation of a Dirhodium(II) Complex. Organometallics 2012, 31, 2907-2913. (i) Ren, S.; Qiu, Z.; Xie, Z., Reaction of Zirconocene-Carboryne with Alkenes: Synthesis and Structure of Zirconacyclopentanes with a Carborane Auxiliary. Organometallics 2012, 31, 4435-4441. (j) Wee, K.-R.; Cho, Y.-J.; Jeong, S.; Kwon, S.; Lee, J.-D.; Suh, I.-H.; Kang, S. O., Carborane-Based Optoelectronically Active Organic Molecules: Wide Band Gap Host Materials for Blue Phosphorescence. J. Am. Chem. Soc. 2012, 134, 17982-17990. (k) Spokoyny, A. M.; Lewis, C. D.; Teverovskiy, G.; Buchwald, S. L., Extremely Electron-Rich, Boron-Functionalized, Icosahedral Carborane-Based Phosphinoboranes. Organometallics 2012, 31, 8478-8481. (1) Lugo, C. A.; Moore, C. E.; Rheingold, A. L.; Lavallo, V., Synthesis of a Hybrid mTerphenyl/o-Carborane Building Block: Applications in Phosphine Ligand Design. Inorg. Chem. 2015, 54, 2094-2096. (m) Naito, H.; Morisaki, Y.; Chujo, Y., o-Carborane-Based Anthracene: A Variety of Emission Behaviors. Angew. Chem., Int. Ed. 2015, 54, 5084-5087. (n) Holmes, J.; Pask, C. M.; Willans, C. E., Chelating N-heterocyclic carbene-carboranes offer flexible ligand coordination to IrIII, RhIII and RuII: effect of ligand cyclometallation in catalytic transfer hydrogenation. Dalton Trans. 2016, 45, 15818-15827. (o) Riley, L. E.; Chan, A. P. Y.; Taylor, J.; Man, W. Y.; Ellis, D.; Rosair, G. M.; Welch, A. J.; Sivaev, I. B., Unprecedented flexibility of the 1,1'bis(o-carborane) ligand: catalytically-active species stabilised by B-agostic B-H $\rightarrow \mathrm{Ru}$ interactions. Dalton Trans. 2016, 45, 1127-1137. (p) Eleazer, B. J.; Smith, M. D.; Peryshkov, D. V., Metal- and Ligand-Centered Reactivity of meta-CarboranylBackbone Pincer Complexes of Rhodium. Organometallics 2016, 35, 106-112.

(3) Scholz, M.; Hey-Hawkins, E. Carbaboranes as Pharmacophores: Properties, Synthesis, and Application Strategies. Chem. Rev. 2011, 111, 7035 - 7062.

(4) Kalinin, V. N. Studies in the Field of Boron-substituted Functional Derivatives of Carbaboranes(12). Russ. Chem. Rev. 1980, 49, 1084 - 1096.

(5) Olid, D.; Núñez, R.; Viñas, C.; Teixidor, F., Methods to produce $\mathrm{B}-\mathrm{C}, \mathrm{B}-\mathrm{P}, \mathrm{B}-\mathrm{N}$ and $\mathrm{B}-\mathrm{S}$ bonds in boron clusters. Chem. Soc. Rev. 2013, 42, 3318-3336.

(6) R. N. Grimes, Carboranes, $3^{\text {rd }}$ ed., Academic Press, New York, 2016.

(7) For recent reviews on B-H functionalizations, see: (a) Dziedzic, R. M.; Spokoyny, A. M. Metal-Catalyzed Cross-Coupling Chemistry with Polyhedral Boranes. Chem. Commun. 
2019, 55, 430-442; (b) Quan, Y.; Xie, X. Controlled Functionalization of $o$-carborane via Transition Metal Catalyzed B - H Activation. Chem. Soc. Rev. 2019, 48, 3660 - 3673; (c) Duttwyler, S., Recent advances in B-H functionalization of icosahedral carboranes and boranes by transition metal catalysis. Pure and Appl. Chem. 2018, 90, 733-744. Selected recent examples, see: (d) Cheng, R.; Li, B.; Wu, J.; Zhang, J.; Qiu, Z.; Tang, W.; You, S.-L.; Tang, Y.; Xie, Z., Enantioselective Synthesis of Chiral-at-Cage o-Carboranes via Pd-Catalyzed Asymmetric B-H Substitution. J. Am. Chem. Soc. 2018, 140, 45084511. (e) Au, Y. K.; Lyu, H.; Quan, Y.; Xie, Z., Catalytic Cascade Dehydrogenative Cross-Coupling of $\mathrm{BH} / \mathrm{CH}$ and $\mathrm{BH} / \mathrm{NH}$ : One-Pot Process to Carborano-Isoquinolinone. J. Am. Chem. Soc. 2019, 141, 12855-12862. (f) Lyu, H.; Zhang, J.; Yang, J.; Quan, Y.; Xie, Z., Catalytic Regioselective Cage B(8)-H Arylation of o-Carboranes via "Cage-Walking" Strategy. J. Am. Chem. Soc. 2019, 141, 4219-4224. (g) Au, Y. K.; Lyu, H.; Quan, Y.; Xie, Z., Copper-Catalyzed Electrochemical Selective B-H Oxygenation of o-Carboranes at Room Temperature. $J$. Am. Chem. Soc. 2020, 142, 6940-6945. (h) Lin, F.; Yu, J.-L.; Shen, Y.; Zhang, S.-Q.; Spingler, B.; Liu, J.; Hong, X.; Duttwyler, S., Palladium-Catalyzed Selective Five-Fold Cascade Arylation of the 12-Vertex Monocarborane Anion by B-H Activation. J. Am. Chem. Soc. 2018, 140, 13798-3807. (i) Zhang, Y.; Wang, T.; Wang, L.; Sun, Y.; Lin, F.; Liu, J.; Duttwyler, S., RhIII-Catalyzed Functionalization of closo-Dodecaborates by Selective B-H Activation: Bypassing Competitive C-H Activation. Chem. Eur. J. 2018, 24, 15812-15817. (j) Shen, Y.; Zhang, K.; Liang, X.; Dontha, R.; Duttwyler, S., Highly selective palladium-catalyzed one-pot, five-fold $\mathrm{B}-\mathrm{H} / \mathrm{C}-\mathrm{H}$ cross coupling of monocarboranes with alkenes. Chem. Sci. 2019, 10, 4177-4184. (k) Eleazer, B. J.; Smith, M. D.; Popov, A. A.; Peryshkov, D. V. (BB)-Carboryne Complex of Ruthenium: Synthesis by Double B-H Activation at a Single Metal Center. J. Am. Chem. Soc. 2016, 138, 10531-10538.(8) (a) Wiesboeck, R. A.; Hawthorne, M. F. Dicarbaundecaborane(13) and Derivatives. J. Am. Chem. Soc. 1964, 86, 1642 - 1643; (b) Hawthorne, M. F.; Young, D. C.; Garrett, P. M.; Owen, D. A.; Schwerin, S. G.; Tebbe, F. N.; Wegner, P. A. Preparation and Characterization of the (3)-1,2- and (3)-1,7-dicarbadodecahydroundecaborate(-1) ions. J. Am. Chem. Soc. 1968, 90, 862; (c) Plesěk, J.; Herm̌ańek, S.; Štibr, B.; Waksman, L.; Sneddon, L. G. Potassium Dodecahydro-7,8-dicarba-nido-undecaborate(1-), $\mathrm{K}\left[7,8-\mathrm{C}_{2} \mathrm{~B}_{9} \mathrm{H}_{12}\right]$, Intermediates, Stock Solution, and Anhydrous Salt. Inorg. Synth 1984, 22, 231. (d) Willans, C. E.; Kilner, C. A.; Fox, M. A., Deboronation and Deprotonation of orthoCarborane with N-Heterocyclic Carbenes. Chem.-Eur. J. 2010, 16, 10644-10648

(9) Dziedzic, R. M.; Axtell, J. C.; Rheingold, A. L.; Spokoyny, A. M., Off-Cycle Processes in Pd-Catalyzed Cross-Coupling of Carboranes. Org. Process Res. Dev. 2019, 23, 1638-1645.

(10) Levit, G. L.; Demin, A. M.; Kodess, M. I.; Ezhikova, M. A.; Sadretdinova, L. S.; Ol'shevskaya, V. A.; Kalinin, V. N.; Krasnov, V. P.; Charushin, V. N., Acidic hydrolysis of N-acyl1-substituted 3-amino-1,2-dicarba-closo-dodecaboranes. $J$ Organomet. Chem. 2005, 690, 2783-2786.

(11) (a) Sevryugina, Y.; Julius, R. L.; Hawthorne, M. F., Novel Approach to Aminocarboranes by Mild Amidation of Selected Iodo-carboranes. Inorg. Chem. 2010, 49, 10627-10634. (b) Beletskaya, I. P.; Bregadze, V. I.; Kabytaev, K. Z.; Zhigareva, G. G.; Petrovskii, P. V.; Glukhov, I. V.; Starikova, Z. A., Palladium-Catalyzed Amination of 2-Iodo-para-carborane. Organometallics 2007, 26, 2340-2347. (c) Mukhin, S. N.;
Kabytaev, K. Z.; Zhigareva, G. G.; Glukhov, I. V.; Starikova, Z. A.; Bregadze, V. I.; Beletskaya, I. P., Catalytic Amidation of 9-Iodo-m-carborane and 2-Iodo-p-carborane at a Boron Atom. Organometallics 2008, 27, 5937-5942.

(12) (a) Grushin, V. V., Carboranylhalonium ions: from striking reactivity to a unified mechanistic analysis of polar reactions of diarylhalonium compounds. Acc. Chem. Res. 1992, 25, 529536. (b) Zhao, D.; Xie, Z., [3- $\left.\mathrm{N}_{2}-o-\mathrm{C}_{2} \mathrm{~B}_{10} \mathrm{H}_{11}\right]\left[\mathrm{BF}_{4}\right]$ : a useful synthon for multiple cage boron functionalizations of ocarborane. Chem. Sci. 2016, 7, 5635-5639.

Spo(13) Dziedzic, R. M.; Saleh, L. M. A.; Axtell, J. C.; Martin, J. L.; Stevens, S. L.; Royappa, A. T.; Rheingold, A. L.; Spokoyny, A. M., B-N, B-O, and B-CN Bond Formation via Palladium-Catalyzed Cross-Coupling of B-Bromo-Carboranes. J. Am. Chem. Soc. 2016, 138, 9081-9084.

(14) Kataki-Anastasakou, A.; Axtell, J. C.; Hernandez, S.; Dziedzic, R. M.; Balaich, G. J.; Rheingold, A. L.; Spokoyny, A. M.; Sletten, E. M., Carborane guests for cucurbit[7]uril facilitate strong binding and on demand removal. ChemRxiv Preprint 2020, ibid.

(15) (a) Ingoglia, B. T.; Wagen, C. C.; Buchwald, S. L., Biaryl monophosphine ligands in palladium-catalyzed $\mathrm{C}-\mathrm{N}$ coupling: An updated User's guide. Tetrahedron 2019, 75, 4199-4211. (b) Ruiz-Castillo, P.; Buchwald, S. L., Applications of PalladiumCatalyzed C-N Cross-Coupling Reactions. Chem. Rev. 2016, 116, 12564-12649. (c) Surry, D. S.; Buchwald, S. L., Biaryl Phosphane Ligands in Palladium-Catalyzed Amination. Angew. Chem., Int. Ed. 2008, 47, 6338-6361.(15) Safety note: plastic spatular was used to weigh the $\mathrm{NaN}_{3}$. When running the reactions, a blast shield was put in front of the reaction vessels as a protective measure.

(16) Grushin, V. V.; Tolstaya, T. P.; Lisichkina, I. N. Bull. Acad. Sci. USSR, Div. Chem. Sci. (Engl. Transl.) 1982, 31, 2329.

(17) Fajardo, J.; Chan, A. L.; Tham, F. S.; Lavallo, V., Synthesis and characterization of anionic polybrominated carboranyl azides. Inorg. Chim. Acta. 2014, 422, 206-208.

(18) Lieber, E.; Rao, C. N. R.; Chao, T. S.; Hoffman, C. W. W. Infrared Spectra of Organic Azides. Anal. Chem. 1957, 29, 916 $-918$.

(19) (a) Kolb, H. C.; Finn, M. G.; Sharpless, K. B., Click Chemistry: Diverse Chemical Function from a Few Good Reactions. Angew. Chem., Int. Ed. 2001, 40, 2004-2021. (b) Rostovtsev, V. V.; Green, L. G.; Fokin, V. V.; Sharpless, K. B., A Stepwise Huisgen Cycloaddition Process: Copper(I)Catalyzed Regioselective "Ligation" of Azides and Terminal Alkynes. Angew. Chem., Int. Ed. 2002, 41, 2596-2599. (c) Wang, C.; Ikhlef, D.; Kahlal, S.; Saillard, J.-Y.; Astruc, D., Metal-catalyzed azide-alkyne "click" reactions: Mechanistic overview and recent trends. Coord. Chem. Rev. 2016, 316, 120. (d) Singh, M. S.; Chowdhury, S.; Koley, S., Progress in 1,3dipolar cycloadditions in the recent decade: an update to strategic development towards the arsenal of organic synthesis. Tetrahedron 2016, 72, 1603-1644.

(20) Rodríguez-Rey, J. L.; Esteban-Gómez, D.; Platas-Iglesias, C.; Sousa-Pedrares, A. Electronic versus Steric Control in Palladium Complexes of Carboranyl PhosphineIminophosphorane Ligands. Dalton Trans. 2019, 48, 486 - 503. (21) Kennedy, R. D. Stabilization of Acyclic Phosphazides using the ortho-closo-didcarbadodecaboranyl residue. Chem. Commun. 2010, 46, 4782 - 4787. 
(22) Cheng, R.; Qiu, Z.; Xie, Z., Iridium-catalysed regioselective borylation of carboranes via direct $\mathrm{B}-\mathrm{H}$ activation. Nat. Commun. 2017, 8, 14827-14833.

(23) (a) Blanch, R. J.; Bush, L. C.; Jones, M., Carboranylnitrenes. Inorg. Chem. 1994, 33, 198-199.

(24) Lyu, H.; Quan, Y.; Xie, Z., Transition Metal Catalyzed Direct Amination of the Cage $\mathrm{B}(4)-\mathrm{H}$ Bond in $o$-Carboranes: Synthesis of Tertiary, Secondary, and Primary $o$-Carboranyl Amines. J. Am. Chem. Soc. 2016, 138, 12727-12730.

(25) Vinogradova, E. V.; Fors, B. F.; Buchwald, S. B. Palladium-Catalyzed Cross-Coupling of Aryl Chlorides with Sodium Cyanate: A Practical Synthesis of Unsymmetrical Ureas. J. Am. Chem. Soc. 2012, 134, 11132 - 11135.

(26) a) For 9-o- and 9-m-carboranylisocyanates, see Ol'shevskaya, V. A.; Zaitsev, A. V.; Ayub, R.; Petrovskii, P. V.; Kononova, E. G.; Tatarskii, Jr., V. V.; Shtil', A. A.; Kalinin, V. N. New 9-Isocyanato-o- and 9-Isocyanato-m-Carboranes: Synthesis and Chemical and Biological Properties. Dolk. Chem. 2005, 405, 230 - 234; b) For a C-bound carboranylisocyanate anion, see Arterburn, J. B.; Wu, Y.; Quintana, W. Synthesis and Characterization of a New Isocyanato Carborane Anion [7$\left.\mathrm{O}=\mathrm{C}=\mathrm{N}-7-\mathrm{CB}_{10} \mathrm{H}_{12}\right]$; Study on Its Reactivity Toward Amino Containing Compounds. Polyhedron 1996, 15, 4355 - 4359; c) For 3-o-carboranylisocyanate, see Zakharkhin, L. I.; Kalinin, V. N.; Gedymin, V. V.; Dzarasova, G. S. Some Reactions of 3Amino-o-Carboranes J. Organomet. Chem. 1970, 23, 303 312; d) For neutral C-bound $o$-carboranylisocyanate, see Kasar, R. A.; Knudsen, G. M.; Kahl, S. B. Synthesis of 3-Amino-1Carboxy-o-Carborane and an Improved, General Method for the Synthesis of All Three C-Amino-C-Carboxycarboranes. Inorg. Chem. 1999, 38, 2936 - 2940; e) For a dodecaborate dianon and a decaborate monoanion bearing an isocyanate group, see Alam, F.; Soloway, A. H.; Barth, R. F.; Mafune, M.; Adams, D. M.; Knoth, W. H. Boron Neutron Capture Therapy: Linkage of a Boronated Macromolecule to Monoclonal Antibodies Directed against Tumor-Associated Antigens. $J$. Med. Chem. 1989, 32, 2326 - 2330 and f) Zhang, Y.; Sun, Y.; Wang, T.; Liu, J.; Spingler, B.; Duttwyler, S. Synthesis and Structural Characterization of Amidine, Amide, Urea and Isocyanate Derivatives of the Amino-closo-dodecaborate Anion $\left[\mathrm{B}_{12} \mathrm{H}_{11} \mathrm{NH}_{3}\right]^{-}$. Molecules 2018, 23, 3137 - 3149 .

(27) Norbury, A. H. Coordination Chemistry of Cyanate, Thiocyanate, and Selenocyanate Ions. Adv. Inorg. Chem. Radiochem. 1975, 17, 231 - 386, and references therein.
(28) Barnett, B. R.; Labios, L. A.; Moore, C. E.; England, J.; Rheingold, A. L.; Wieghardt, K.; Figueroa, J. S., Solution Dynamics of Redox Noninnocent Nitrosoarene Ligands: Mapping the Electronic Criteria for the Formation of Persistent Metal-Coordinated Nitroxide Radicals. Inorg. Chem. 2015, 54, 7110-7121.

(29) Davison, W. H. T. Infra-red Absorptions of the Isocyanate Group. J. Chem. Soc. 1953, 3712 - 3713.

(30) Oliva, J. M.; Allan, N. L.; Schleyer, P. v. R.; Viñas, C.; Teixidor, F. Strikingly Long $\mathrm{C} \cdots \mathrm{C}$ Distances in 1,2Disubstituted ortho-Carboranes and Their Dianions. Organometallics 2005, 127, 13538 - 13547.

(31) Wu, Y.; Carroll, P. J.; Kang, S. O.; Quintana, W. Synthesis, Characterization, and Reactivity of Isocyanato Dicarbaboranes Obtained from o-Carborane Inorg. Chem. 1997, 36, 4753 4761 .

(32) Monsanto Company, "Isocyanates Containing TertiaryAlkyl Groups" US310131A, 1964.

(33) a) Yruegas, S.; Axtell, J. C.; Kirlikovali, K. O.; Spokoyny, A. M.; Martin, C. D. Synthesis of 9-Borafluorene Analogues Featuring a 1,1'-Bis(o-carborane) Backbone. Chem. Commun. 2019, 55, 2892 - 2895; b) Fisher, S. P.; McArthur, S. G.; Tej, V.; Lee, S. E.; Chan, A. L. Banda, I.; Gregory, A.; Berkley, K.; Tsay, C.; Rheingold, A. L.; Guisado-Barrios, G.; Lavallo, V. Strongly Coordinating Ligands to Form Weakly Coordinating Yet Functional Organometallic Anions. J. Am. Chem. Soc. 2020, 142, 251 - 256; c) Nuñez, R.; Tarrés, M.; Ferrer-Ugalde, A.; de Bilani, F. F.; Teixidor, F. Electrochemistry and Photoluminescence of Icosahedral Carboranes, Boranes, Metallacarboranes, and Their Derivatives. Chem. Rev. 2016, 116, 14307 - 14378; d) Stockmann, P.; Gozzi, M.; Kuhnert, R.; Sárosi, M. B.; Hey-Hawkins, E. New Keys for Old Locks: Carborane-Containing Drugs as Platforms for MechanismBased Therapies. Coord. Chem. Rev. 2019, 48, 3497 - 3512. 


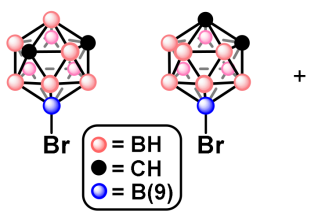

diverse $\mathbf{N}$-nucleophiles

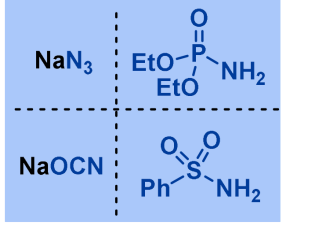

$\frac{\mathrm{Pd} / \mathrm{L}, \mathrm{K}_{3} \mathrm{PO}_{4}}{\mathrm{DME}, 80^{\circ} \mathrm{C}}$

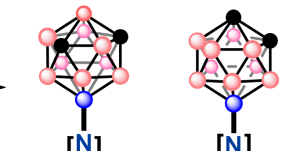

unified approach towards carborane B(9) amination 